\title{
A standardized framework to evaluate the quality of studies using TDABC in healthcare: the TDABC in Healthcare Consortium Consensus Statement
}

\author{
Ana Paula Beck da Silva Etges ${ }^{1,2,3,4^{*}}$ (D), Carisi Anne Polanczyk ${ }^{1,3,4,5}$ and Richard D. Urman ${ }^{4,6,7}$
}

\begin{abstract}
Background: This Consensus Statement introduces a standardized framework, in a checklist format, to support future development and reporting of TDABC studies in healthcare, and to encourage their reproducibility. Additionally, it establishes the first formal networking of TDABC researchers through the creation of the TDABC in Healthcare Consortium.

Methods: A consensus group of researchers reviewed the most relevant TDABC studies available in Medline and Scopus databases to identify the initial elements of the checklist. Using a Focus Group process, each element received a recommendation regarding where in the scientific article section it should be placed and whether the element was required or suggested. A questionnaire was circulated with expert researchers in the field to provide additional recommendations regarding the content of the checklist and the strength of recommendation for each included element.

Results: The TDABC standardized framework includes 32 elements, provides recommendations where in the scientific article to include each element, and comments on the strength of each recommendation. All 32 elements were validated, with 21 elements classified as mandatory and 11 as suggested but not mandatory.

Conclusions: This is the first standardized framework to support the development and reporting of TDABC research in healthcare and to stablish a community of experts in TDABC methodology. We expect that it can contribute to scale strategies that would result in cost-savings outcomes and in value-oriented strategies that can be adopted in healthcare systems and institutions.
\end{abstract}

Keywords: Time-driven activity based costing, Value-based healthcare, TDABC, VBHC, Microcosting, Healthcare costs

\footnotetext{
* Correspondence: anabsetges@gmail.com

${ }^{1}$ National Institute of Science and Technology for Health Technology

Assessment (IATS)- CNPq/Brazil (project: 465518/2014-1), Ramiro Barcelos

2350, Porto Alegre, Brazil

${ }^{2}$ School of Technology, Pontifícia Universidade Católica do Rio Grande do

Sul, Porto Alegre, Brazil

Full list of author information is available at the end of the article
}

(C) The Author(s). 2020 Open Access This article is licensed under a Creative Commons Attribution 4.0 International License, which permits use, sharing, adaptation, distribution and reproduction in any medium or format, as long as you give appropriate credit to the original author(s) and the source, provide a link to the Creative Commons licence, and indicate if changes were made. The images or other third party material in this article are included in the article's Creative Commons licence, unless indicated otherwise in a credit line to the material. If material is not included in the article's Creative Commons licence and your intended use is not permitted by statutory regulation or exceeds the permitted use, you will need to obtain permission directly from the copyright holder. To view a copy of this licence, visit http://creativecommons.org/licenses/by/4.0/ The Creative Commons Public Domain Dedication waiver (http://creativecommons.org/publicdomain/zero/1.0/) applies to the data made available in this article, unless otherwise stated in a credit line to the data. 


\section{Background}

The use of Time-Driven Activity-Based Costing (TDABC) methodology to evaluate costs in healthcare has expanded in the last 5 years, with studies encompassing different healthcare fields such as surgery and perioperative care [1, $2]$, cancer [3], transplants [4, 5], outpatient care [6], psychiatry [7], and hospital management [8] as reported in recent systematic reviews $[9,10]$. The increasing number of TDABC studies suggests that this is an essential method for supporting value-based healthcare management programs [11-13]. In fact, in 2020 the Society for Perioperative Assessment and Quality Improvement (SPAQI) outlined eight principles of TDABC and argued that the aforementioned method provides cost transparency to demonstrate value in perioperative care [14]. Even though the use of TDABC has advanced, its application in microcosting studies in healthcare presents methodological heterogeneity and demonstrates differences in how researchers design studies and report their methods and results $[9,15]$.

The International Society for Pharmacoeconomic and Outcomes Research (ISPOR) recently revised the Consolidated Health Economic Evaluation Reporting Standards (CHEERS) statement, which provides recommendations to optimize the reporting of health economic evaluations [16]. The CHEERS statement provides a list of 24 items that a scientific article on economic evaluation should contain. However, specific items in the list that guide cost reporting, i.e. "estimating resources and costs (13a and 13b)" and "Incremental costs and outcomes (19)" lack detailed methods to achieve high quality and real individual cost information. The use of bottom-up microcosting techniques are described in the literature as the "gold-standard" recommendation to evaluate the cost information in economic analyses $[17,18]$, and the TDABC methodology can be used to better perform the microcosting studies $[9,15]$.

This Consensus Statement aims to provide a standardized framework, in a checklist format, to support future development and reporting of TDABC studies in healthcare. This checklist is not intended to be a rigid guideline, but rather as a tool to assist researchers when designing and reporting TDABC studies. It should prompt reviewers and readers to question the lack or appropriateness of certain elements when developing a healthcare-related TDABC project.

Our overall goal is to encourage reproducibility in TDABC studies, while taking into account the different variables that may influence cost analysis and the different ways in which TDABC has been implemented in microcosting studies around the world. In addition, this Consensus Statement aims to establish a global community of TDABC researchers through the creation of the TDABC for Healthare Consortium (www.tdabcconsortium.com).

\section{Methods}

The overall methodology was based, at least in part, on other recent checklists used for reporting study results [19]. Our approach consisted of four phases: (i) Selection of TDABC expert researchers and identification of initial elements of the checklist; (ii) Application of a Focus Group process to build the checklist [15]; (iii) Selection of external opinions to validate the checklist; (iv) Creation of the checklist. Each phase involved different researchers who were categorized into the following groups: leaders of the consensus group (3 researchers: A.P.E., C.A.P., and R.D.U.); the consensus group (3 leaders and two additional researchers); and the TDABC consulting researchers (17 researchers invited to answer the questionnaire). Therefore, during the checklist development process, a total of 22 experts including researchers, clinicians and healthcare managers were involved. Figure 1 is a flowchart which details the sequence of consensus phases, the types of participants who were involved in each phase, techniques applied, and the results following each phase. Each of the four phases is described in more detail below.

\section{Selection of TDABC expert researchers and identification of initial elements of the checklist}

The authors of this article represent the leaders of the consensus group, responsible for the design and management of the checklist. The TDABC methodology [19] and the 8-step framework applied in TDABC microcosting studies [4] were used as guides to create the checklist element sequence. The checklist element sequence was created by posing a question to the participant which required a binary answer ("yes" or "no"). This approach was used to help future checklist users to assess each element when reviewing a TDABC in healthcare study.

Next, the 15 most cited cost analyses or management studies that detailed opportunities in applying TDABC in healthcare, available in Scopus database, were reviewed to identify the presence of each element in the studies. The keywords "Time-Driven Activity-Based Costing" OR "TDABC" and "Health" were used to search for the articles. Studies with a high citation but that only reported the TDABC as a cost analysis strategy used while not detailing its application, were not considered (10 articles see Additional file 1). Those articles commented on the method theoretically but did not apply it in a real-world setting. The articles used in this Consensus statement contained at least 21 citations. Each element in the articles was categorized, where "Required" was attributed to the elements encountered in all studies, and "suggested" attributed for elements encountered in only a few studies.

Since a few studies aimed to assess costs or compare the TDABC with traditional cost methods (Type I) [2022 ] and others aimed to apply TDABC to support 


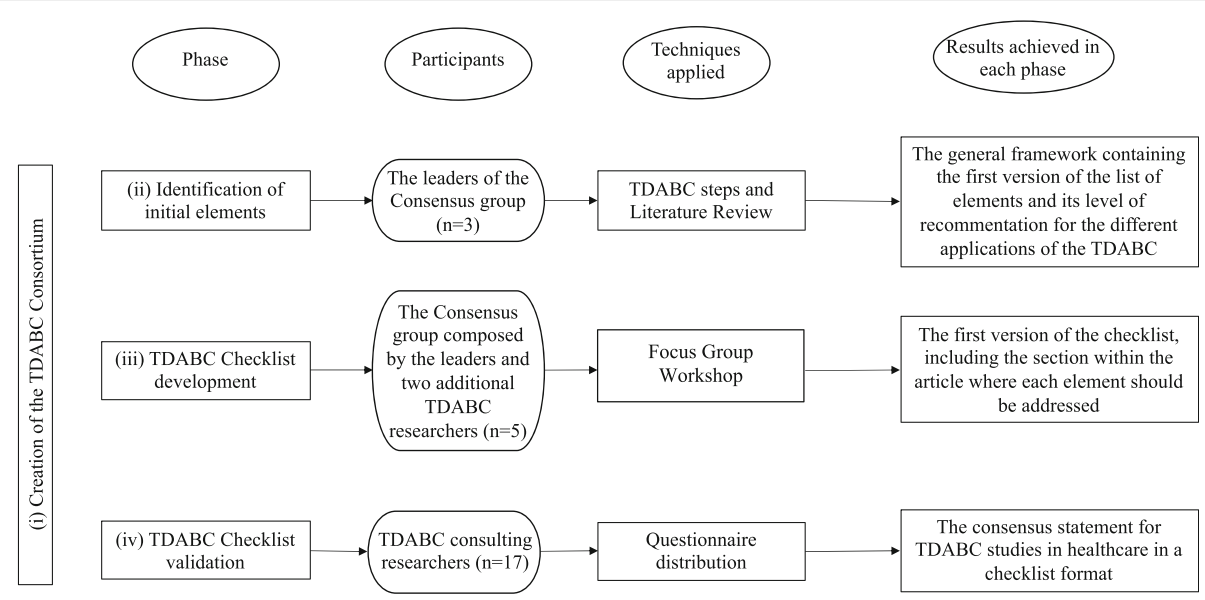

Fig. 1 Sequence of methodological steps followed to develop a standardized framework consensus to evaluate the quality of studies using TDABC in healthcare

healthcare service management (Type II) [23-25], the elements were further classified as follows: (\#) for elements suggested by all studies; (*) for cost assessment (Type I); and (\#*) for management (Type II).

\section{Application focus group process to build the checklist}

The consensus group, formed by the project leaders and two additional researchers with significant experience in TDABC, evaluated the framework in a Focus Group section. The workshop was organized to develop and clarify the elements in the checklist and to define the best section in a research study to place each element. The group followed the sequence of reiterative steps suggested by existing Focus Group methodology for health and medical research [26]. The moderator (A.P.E.) used the researchers' current experiences from different projects that are using TDABC to evaluate hospital costs of the bone marrow transplant treatment [4] and a telemedicine service [27] in Brazil, to facilitate the review and discussion of each element.

For the Focus Group workshop, first the moderator explained the goals of the checklist and presented the proposed elements. Next, each researcher was invited to: classify the level of importance of each element using a 5-point scale for rating [28] (1- it is not important and 5 - it is extremely important); identify if the element was important for all studies, or specific to Type I (studies that applied the TDABC only to assess costs) or Type II (studies that applied the TDABC to support healthcare service management); and identify the most appropriate section in the publication to place each element. Researchers received $1 \mathrm{~h}$ to individually complete the first stage. Subsequently, a discussion section using the experiences from the bone marrow transplant [4] and telemedicine [27] projects was carried out by a moderator who encouraged the interaction without creating bias
[29]. For any disagreement among members, the researchers discussed their areas of disagreement and reached a consensus based on the examples that were encountered during the research group members' recent experiences with TDABC studies $[4,5,27]$ and the results encountered in the recent systematic review developed by the leaders of the consensus group [15].

With the results generated in the workshop section, the consensus group then discussed the framework to incorporate additional best practice elements.

\section{Selection of external opinions to validate the checklist}

The TDABC study checklist was distributed to authors of prior key TDABC studies, which were identified in our most recent systematic review [15] exploring TDABC in healthcare as well as to authors who frequently published studies using this methodology. A total of 17 published authors included researchers with Master's and Doctoral degrees from North and South America, Europe, Oceania and Africa who collaborated by answering a Google Forms questionnaire (Appendix). The questionnaire contained five possible responses to define whether an element fell into one of the following categories: (i) Mandatory; (ii) Strongly suggested, but not mandatory; (iii) Suggested; (iv) Optional; (5) Do not include. The interviewees were invited to answer the questionnaire and consented to participate by having their opinions provided in the questionnaire to be included in the research analysis.

\section{Creation of the checklist}

The answers were combined into a spreadsheet by the consensus group for data analysis. The frequency for each selected answer was used as the criterion to define the strength of recommendation for each element, so that the strength of recommendation suggested by the 
majority of those interviewed regarding each element was used to define the final strength of recommendation. A final framework including 32 elements, the strength of each recommendation, and the location within the article where each element should be addressed, was used to generate the final framework version to evaluate the quality of studies using TDABC.

The researchers involved in all phases of this project represent the initial members of the newly-formed TDABC in Healthcare Consortium (www.tdabcconsotium.com). The Consortium is composed of a collaborative group of researchers and managers who are working to improve the quality of projects that apply TDABC in healthcare and disseminate methodological advances for TDABC to promote value-based healthcare (VBHC).

\section{Results}

Selection of TDABC expert researchers and identification of initial elements of the checklist

The general framework containing elements to guide the reporting of TDABC in healthcare studies includes the revised literature results used to classify the elements (Table 1). The first column depicts the TDABC steps, the second contains the elements, and the third indicates if the element is classified as "required" or "suggested". The symbol (eg. \#, *, \#*) coding indicates if the element is recommended for all studies (\#), only for Type I (*) or only Type II (\#*).

The results shown in Table 1 were the elements identified in all reviewed studies such as the justification for the use of TDABC, the involvement of a multidisciplinary team, the use of formal interviews and observations in situ, the representation of the patient flow at a macro level in a process map, and the connection with value in healthcare decisions. On the other hand, we identified significant heterogeneity in how the TDABC methodological steps were being followed in the studies, such as the patient flow map design, the financial data used (hospital, or external databases) and its level of detail, the inclusion of overhead costs, ways to estimate capacities, time data collection, and approaches used to report the results.

\section{Application of focus group process to build the checklist} By applying the Focus Group process in the first round, we identified two different answers at a level of 2 point-difference and eight different answers at a level of 1 point-difference to confirm the level of importance of each element. We also determined the section within the published study where each element should be placed and if the placement was found in "All studies" (\#), only Type I (*), or only Type II $(\#)$. We reached the consensus for both of these questions after the first round. The divergencies of opinion observed during the first round regarding the level of importance of each item were discussed and, in the second round, a consensus was reached for all of them. Finally, suggestions of additional elements that should be included were discussed. The ones agreed upon by the consensus group were included in the checklist (bold letters in Tables 2 and 3 ). The TDABC elements, differences in opinion, the final consensus reached about level of importance, Type category and suggested paper section are shown in Table 2.

Three elements, which were reported differently by previous authors, were considered of lower level of importance (level 2) during our consensus process. In contrast, while studies reviewed on Table 1 identified elements as common, at the workshop they were considered important (level "5") by consensus. Additionally, it is important to point out that this methods section concentrates on where the majority of elements should be addressed (16 of 32 elements).

\section{Addition of external opinions and creation of the checklist}

Based on the data obtained from the questionnaire, we confirmed the strength of the recommendation for each element in the framework that may be used to guide future TDABC in healthcare studies. Twenty-one elements were judged to be "Mandatory" and 11 elements were "Strongly Suggested but not Mandatory". A few elements received one or two "Do not include" recommendations. However, we did not exclude the elements because of the "majorities' opinion" criteria, which was used to define the strength of recommendation for each element. Table 3 shows the standardized TDABC framework to support the development and reporting of TDABC studies in healthcare.

All the elements that should be placed in the methods section were confirmed as mandatory, as was previously suggested by the level of importance registered in the Focus Group workshop, with only one exception for the element of currency and discount taxes. For this specific element, once the framework is applied to support multiregional or multiperiod cost analyses, it is important to use the most current inflation information available on the world data bank website (https://data.worldbank.org/) to achieve accurate cost information and to compare costs. The following elements were all classified as mandatory and suggested to be placed in the methods section: patient flow map design, financial data used (hospital, or external databases) and its level of detail, the inclusion of overhead costs, the method used to estimate capacities, and the time data collection. 


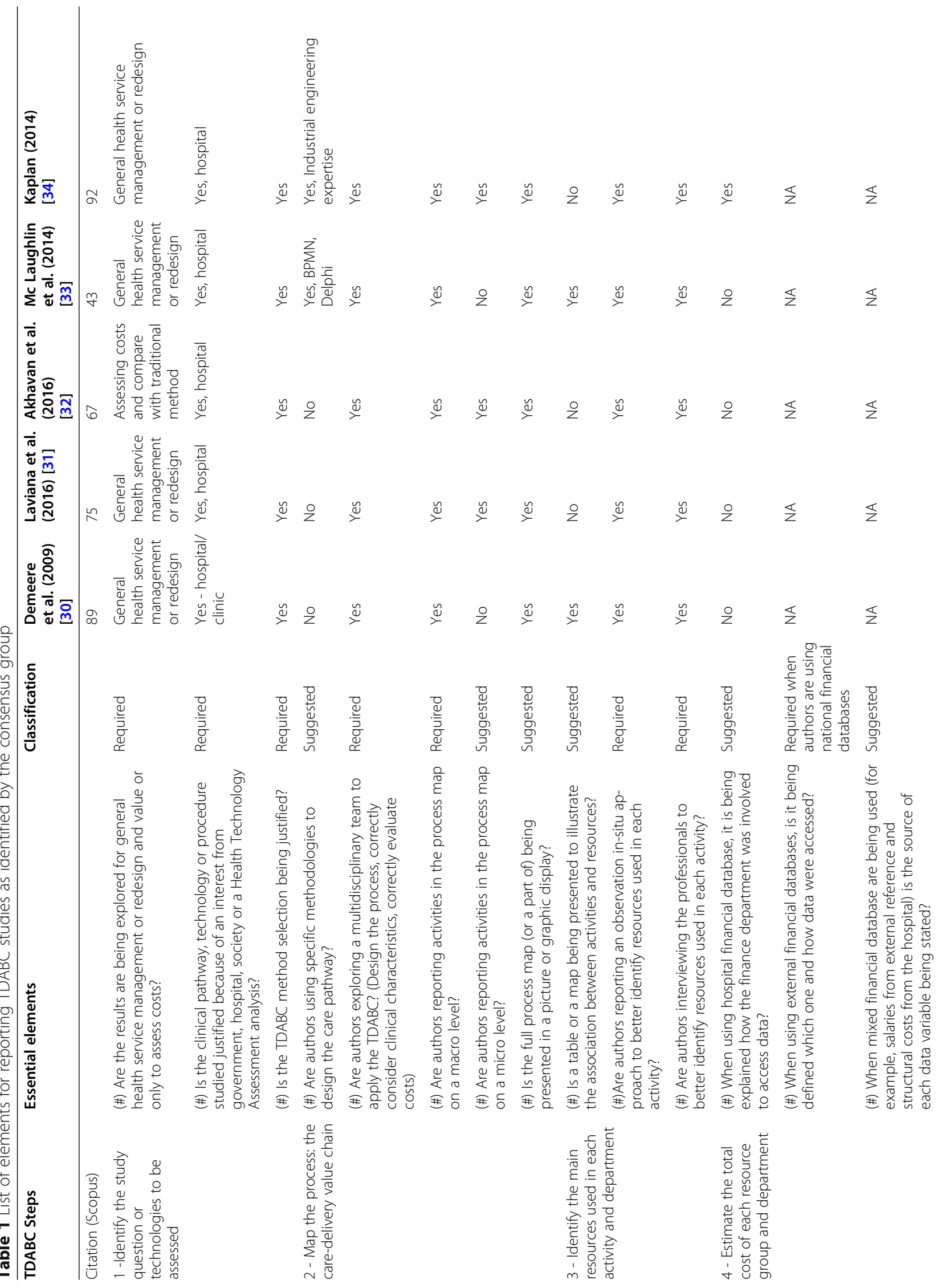




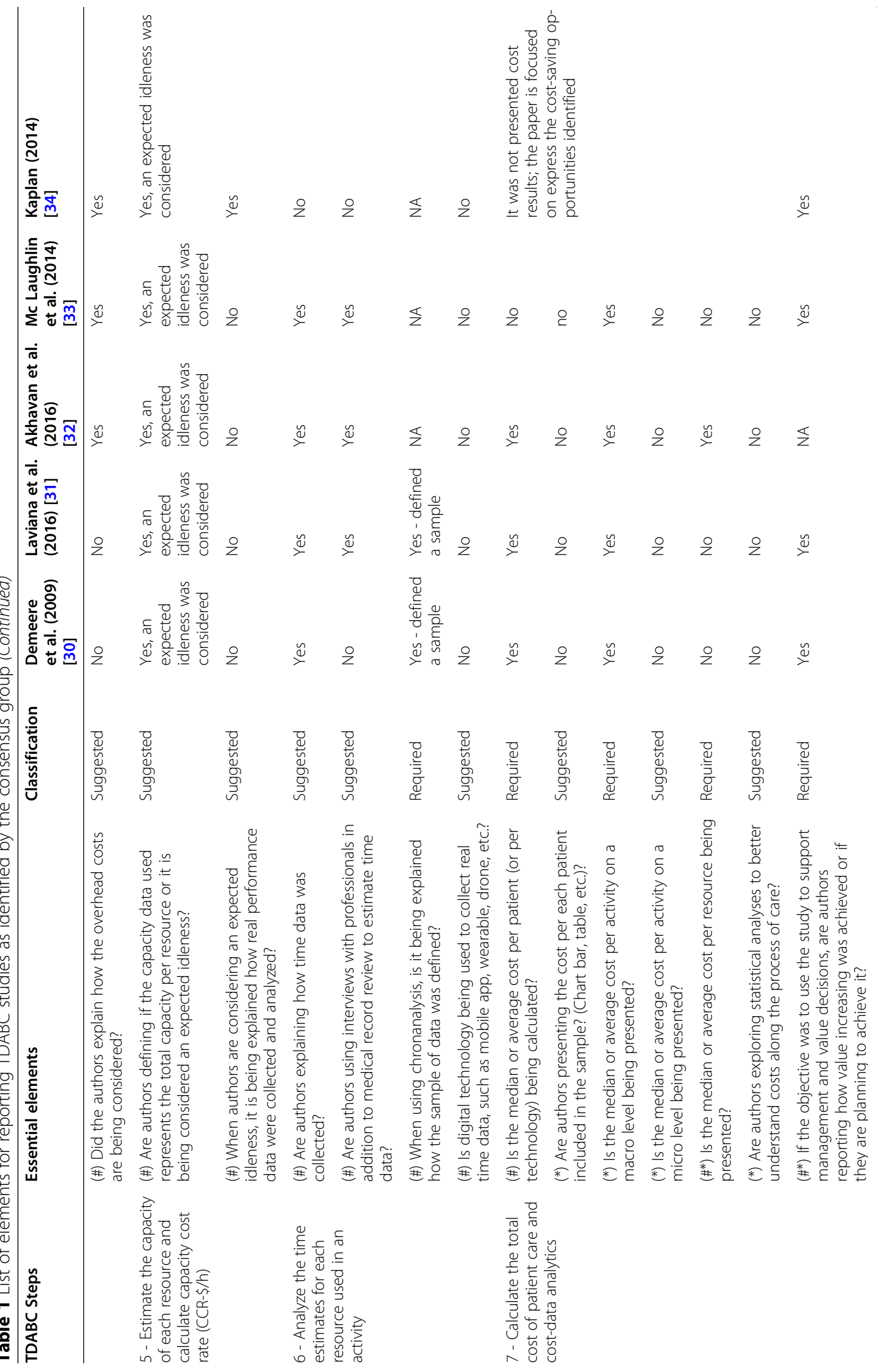




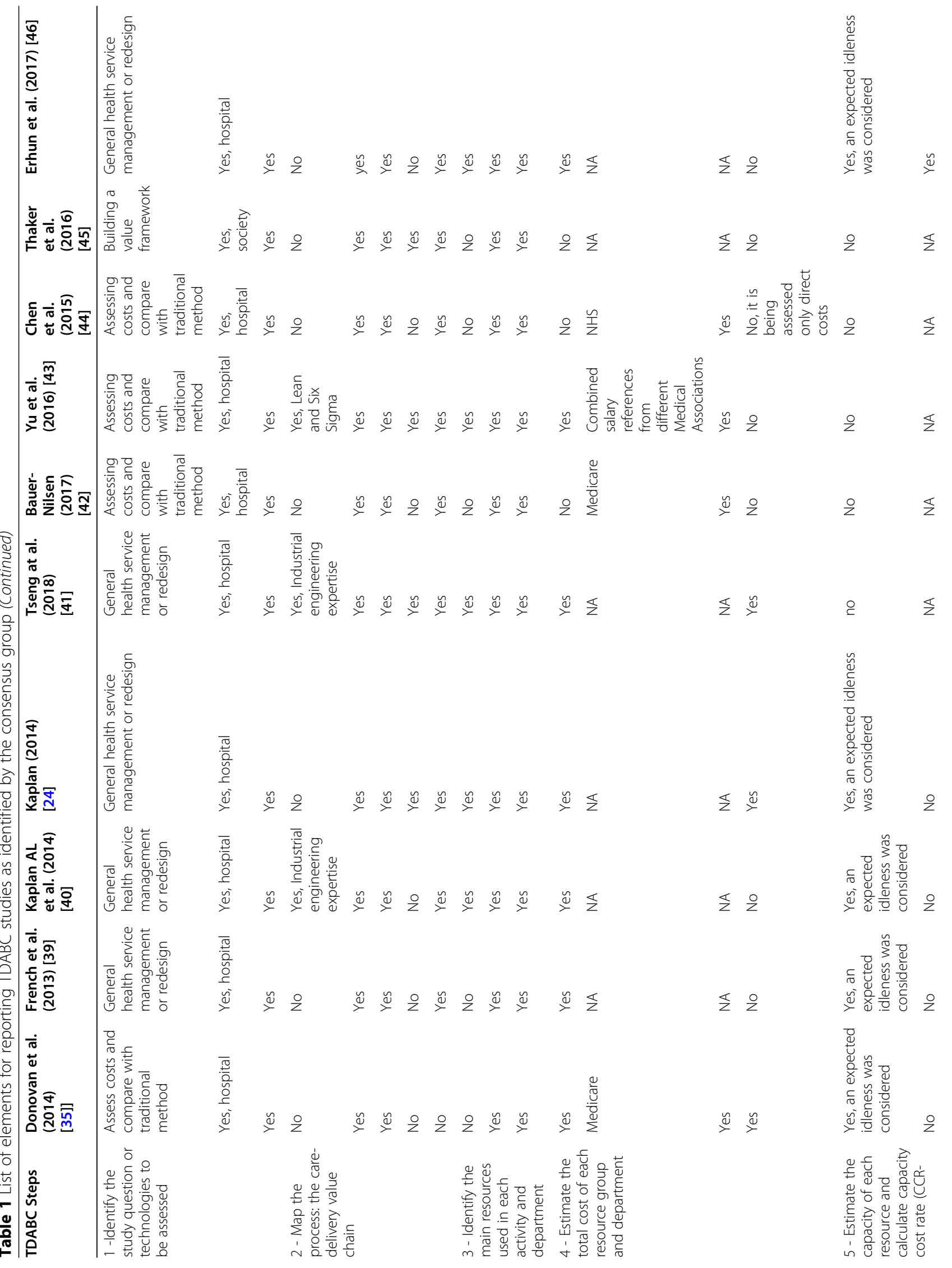




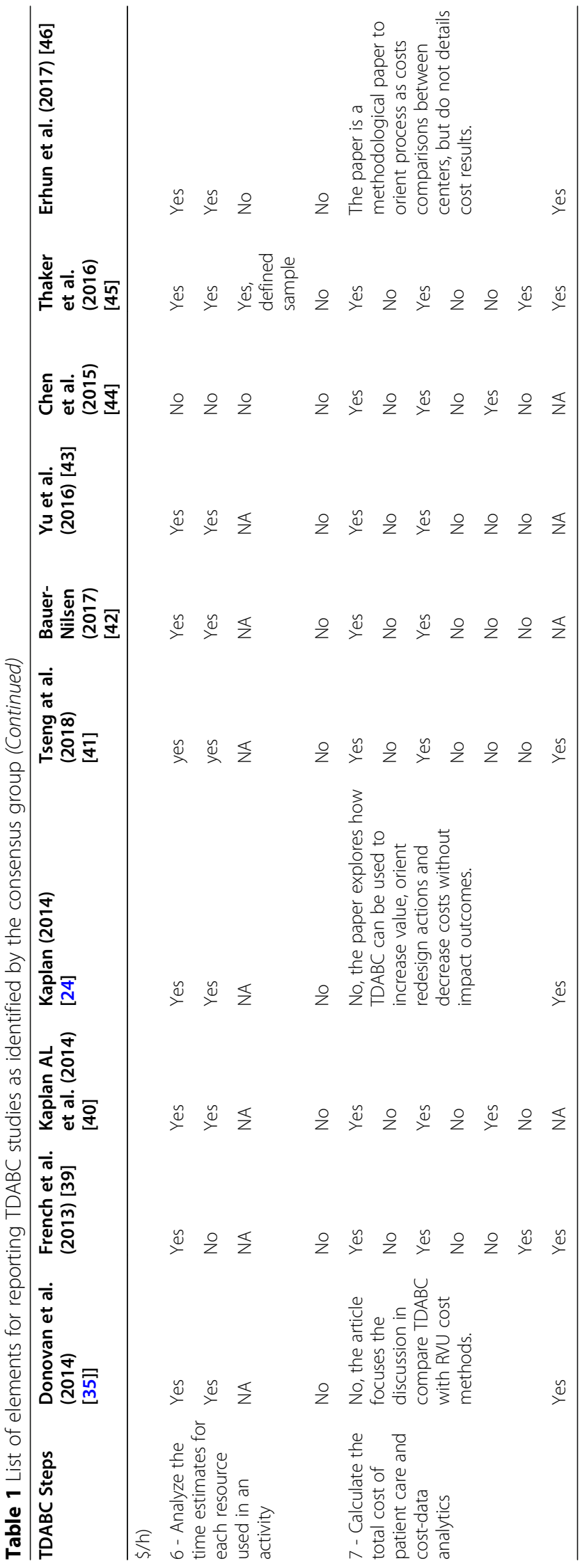


Table 2 The checklist with TDABC elements after the Delphi workshop

TDABC elements
(\#) $1.1 \mathrm{It}$ is defined if the results are being explored for general health service management
or redesign and value or only to assess costs?

(\#)1.2 Is the clinical pathway, technology or procedure studied justified because of an interest from government, hospital, society or a Health Technology Assessment analysis?

\section{(\#)1.3 Are study limitations being presented?}

(\#)1.4 Is the TDABC method selection being justified?

(\#) 2.1 Are authors using specific methodologies to design the care pathway?

(\#) 2.2 Are authors using a multidisciplinary team to apply the TDABC? (Design the process, correctly consider clinical characteristics, correctly evaluate costs.)

(\#) 2.3 Are authors reporting activities in the process map on a macro level?

(\#) 2.4 Are authors reporting activities in the process map on a micro level?

(\#) 2.5 Is the full process map (or a part of) being presented in a picture or graphic display?

(\#) 3.1 Is a table or a map being presented to illustrate the association between activities and resources?

(\#) 3.2 Are resources that are included in the analysis being defined and justified?

(\#) 3.3 Are authors reporting observation in-situ approach to better identify resources used in each activity?

(\#) 3.4 Are authors interviewing the professionals to better identify resources used in each activity?

(\#) 4.1 When using hospital financial database, it is being stated how those data were collected and analyzed?

(\#) 4.2 Are authors defining the currency and applying discount taxes when it is necessary?

(\#) 4.3 When using external financial databases, is there a description of the database and how those data were accessed?

(\#) 4.4 When mixed financial database data are being used (for example, salaries from external reference and structural costs from the hospital) is the origin of each data variable being stated?

(\#) 4.5 Did the authors explain how the overhead costs are being considered?

(\#) 5.1 Are authors defining if the capacity data used represents the total capacity per resource or it is being considered an expected idleness?

(\#) 5.2 When authors are considering an expected idleness, it is explained how actual performance data were collected and analyzed?

(\#) 6.1 Do authors explain how time data were collected?

(\#) 6.2 Are authors using interviews with professionals crossed with medical record review to estimate time data?

(\#) 6.3 When using chronanalysis, it is being explained how the sample of data was defined?

(\#) 6.4 Is it being explained if the chronanalysis used digital technology to collect real time data, such as a mobile app, wearable, drone, etc.?

(\#) 7.1 Is the median or average cost per patient (or per technology) being calculated?

${ }^{*}$ ) 7.2 Are authors presenting the cost per each patient that is included in the sample? (Chart bar, table, etc.)?

$\left.{ }^{*}\right) 7.3$ Is the median or average cost per activity on a macro level being presented?

\begin{tabular}{|c|c|c|c|}
\hline $\begin{array}{l}\text { Paper } \\
\text { section }\end{array}$ & $\begin{array}{l}\text { Researcher } \\
\text { A }\end{array}$ & $\begin{array}{l}\text { Researcher } \\
\text { B }\end{array}$ & Consensus \\
\hline Introduction & 5 & 5 & 5 \\
\hline Introduction & 5 & 5 & 5 \\
\hline Discussion & \multicolumn{2}{|c|}{$\begin{array}{l}\text { Element suggested by the } \\
\text { participants of the Delphi } \\
\text { workshop }\end{array}$} & 5 \\
\hline Introduction & 5 & 3 & 3 \\
\hline Methods & 3 & 3 & 3 \\
\hline Methods & 5 & 5 & 5 \\
\hline Methods & 5 & 5 & 5 \\
\hline Methods & 2 & 2 & 2 \\
\hline Results & 3 & 4 & 4 \\
\hline Results & 3 & 4 & 3 \\
\hline Methods & \multicolumn{2}{|c|}{$\begin{array}{l}\text { Element suggested by the } \\
\text { participants of the Delphi } \\
\text { workshop }\end{array}$} & 3 \\
\hline Results & 5 & 3 & 4 \\
\hline Results & 5 & 4 & 4 \\
\hline Methods & 2 & 2 & 2 \\
\hline Methods & \multicolumn{2}{|c|}{$\begin{array}{l}\text { Element suggested by the } \\
\text { participants of the Delphi } \\
\text { workshop }\end{array}$} & 4 \\
\hline Methods & 5 & 5 & 5 \\
\hline Methods & 5 & 4 & 4 \\
\hline Methods & 3 & 3 & 3 \\
\hline Methods & 5 & 5 & 5 \\
\hline Methods & 3 & 4 & 3 \\
\hline Methods & 5 & 5 & 5 \\
\hline Methods & 5 & 4 & 4 \\
\hline
\end{tabular}

Methods

Element suggested by the 5 participants of the Delphi workshop

Methods

Element suggested by the 4 participants of the Delphi workshop

Result and

Discussion

Result and

Discussion

Result and

Discussion
5

3

5

5

5

5

5


Table 2 The checklist with TDABC elements after the Delphi workshop (Continued)

\begin{tabular}{|c|c|c|c|c|}
\hline TDABC elements & $\begin{array}{l}\text { Paper } \\
\text { section }\end{array}$ & $\begin{array}{l}\text { Researcher } \\
\text { A }\end{array}$ & $\begin{array}{l}\text { Researcher } \\
\text { B }\end{array}$ & Consensus \\
\hline$\left(^{*}\right) 7.4$ Is the median or average cost per activity on a micro level being presented? & $\begin{array}{l}\text { Result and } \\
\text { Discussion }\end{array}$ & 3 & 3 & 3 \\
\hline$\left(^{*}\right) 7.5$ Is the median or average cost per resource being presented? & $\begin{array}{l}\text { Result and } \\
\text { Discussion }\end{array}$ & 3 & 4 & 3 \\
\hline$\left(\#^{*}\right) 7.6$ Are the authors performing capacity idleness analysis? & $\begin{array}{l}\text { Result and } \\
\text { Discussion }\end{array}$ & \multicolumn{2}{|c|}{$\begin{array}{l}\text { Element suggested by the } \\
\text { participants of the Delphi } \\
\text { workshop }\end{array}$} & 2 \\
\hline $\begin{array}{l}\left.{ }^{*}\right) 7.7 \text { Are the authors exploring statistical analyses to better understand costs along the } \\
\text { process of care? }\end{array}$ & $\begin{array}{l}\text { Result and } \\
\text { Discussion }\end{array}$ & 3 & 3 & 3 \\
\hline $\begin{array}{l}\text { (\#) } 7.8 \text { If the objective was to use the study to support management and value decisions, } \\
\text { are authors reporting how value increasing was achieved or if they are planning to achieve } \\
\text { it? }\end{array}$ & $\begin{array}{l}\text { Result and } \\
\text { Discussion }\end{array}$ & 5 & 5 & 5 \\
\hline
\end{tabular}

The column 'Researcher $A^{\prime}$ contains the answers attributed by one of the additional researchers using the scale 1-5 (1- it is not important and 5 - it is extremely important). The column 'Researcher B' contains the answers attributed by the other additional researcher using the scale 1-5. The columns consensus contains the final level of importance accorded between the two researchers and moderator.

\section{Discussion}

The principles of Value-based Healthcare (VBHC) include strategies for alleviating the burden of high expenses in healthcare [13, 30, 36]. However, for successful implementation of VBHC interventions, it is important to achieve accuracy on cost information [31]. This Consensus Statement is the first to introduce a standardized framework, in a checklist format, to support the development and reporting of TDABC studies in healthcare.

The use of advanced costing methods in healthcare offers an opportunity for researchers to fully explore alternatives to improve allocation of public healthcare resources [10]. The group's recent systematic review about TDABC in the VBHC context identified 17 studies that used the TDABC to increase value in healthcare by assessing cost-savings throughout the optimization of the episode of care-cycle [15]. Even though the TDABC was already defined as the "gold standard" to assess real costs in healthcare, the application of TDABC in scientific studies showed enormous variability on how the methodology has been employed $[9,15]$. To solve this problem, we developed the framework that consolidated methodological guidance for the application of TDABC. By following the framework, it is expected that those who design the studies and interpret the results can achieve better accuracy on cost information, understand limitations of some of these studies, and identify opportunities to reduce waste along the episodes of care, all contributing to the expansion of VBHC programs that include more precise cost outcomes assessment.

Neglecting certain costs or adopting inaccurate methodologies for cost estimations can introduce bias in interpretation of the results in health economic studies [32]. As a result of our Focus Group process, it is important to note the significance attributed to the proposed elements described in the methods section. The elements suggested to be posted in the given research study method section were classified as "Mandatory" and only one as "Strongly suggested, but not mandatory". The researchers involved in the workshop process discussed the importance of detailed reporting of the essential elements to make the TDABC results valuable and replicable for future economic analyses, with the understanding that valid valuebased comparisons are not possible without consensus around how costs were being calculated [32]. The strength of the recommendations regarding the methods elements based on the questionnaire responses highlights the importance of detailing of each step followed when applying the TDABC methodology. This guarantees the rigor of the TDABC use to assess costs (Type I) or to support healthcare service management (Type II).

One important issue when applying advanced cost methods is to define the scope, objective and business context where the study is being applied [33]. If the study is specific to assessing costs, the requirements can be more focused on financial aspects; on the other hand, once the method is being used to support healthcare service management, the results and discussion may explore the costsavings and efficiency increase opportunities [37]. The identification of elements that are recommended for all TDABC studies (Type I and Type II) and others specific for Type I or Type II studies is the approach that we suggested in the tool to guide future authors to better consolidate results from their TDABC projects, considering the management and cost assessment or only the cost assessment objective.

In all studies reviewed to introduce the consensus elements, multidisciplinary teams were used to implement the TDABC, which suggests that the individual economic and financial backgrounds vary among the team members. The establishment of transparent communication when dealing with several backgrounds is not an easy task; the terms and definitions usually vary among physicians, engineers, economists, and others. The 
Table 3 The consensus statement for TDABC studies in healthcare in a checklist format

\begin{tabular}{|c|c|c|c|c|c|c|c|}
\hline TDABC elements & Mandatory & $\begin{array}{l}\text { Strongly } \\
\text { suggested, } \\
\text { but not } \\
\text { mandatory }\end{array}$ & Suggested & Option & $\begin{array}{l}\text { Do not } \\
\text { include }\end{array}$ & Classification & $\begin{array}{l}\text { Paper } \\
\text { section }\end{array}$ \\
\hline
\end{tabular}

(\#) 1.1 It is defined if the results are being explored for general health service management or redesign and value or only to assess costs?

(\#) 1.2 Is the clinical pathway, technology or procedure studied justified because of an interest from government, hospital, society or a Health Technology Assessment Analysis?

(\#) 1.3 Are study limitations being presented?

(\#) 1.4 Is the TDABC method selection being justified? 59\%

(\#) 2.1 Are authors using specific methodologies to $\quad 47 \%$ design the care pathway?

(\#) 2.2 Are authors using a multidisciplinary team to apply the TDABC? (Design the process, correctly consider clinical characteristics, correctly evaluate costs)

(\#) 2.3 Are authors reporting activities in the process map on a macro level?

(\#) 2.4 Are authors reporting activities in the process map on a micro level?

(\#) $2.5 \mathrm{Is}$ the full process map (or a part of) being presented in a picture or graphic display?

(\#) 3.1 Is a table or a map being presented to illustrate the association between activities and resources?

(\#) 3.2 Are the resources that are included in the analysis being defined and justified?

(\#) 3.3 Are authors reporting observation in-situ approach to better identify resources used in each activity?

(\#) 3.4 Are the authors interviewing the professionals to better identify resources used in each activity?

(\#) 4.1 When using hospital financial database, it is being stated how those data were collected and analyzed?

(\#) 4.2 Are authors defining the currency and applying discount taxes when it is necessary?

(\#) 4.3 When using external financial databases, is there a description of the database and how those data were accessed?

(\#) 4.4 When mixed financial databases are being used (for example, salaries from external reference and structural costs from the hospital) is the origin of each data variable being stated?

(\#) 4.5 Did the authors explaining how the overhead costs are being considered?

(\#) 5.1 Are authors defining if the capacity data used represents the total capacity per resource or it is being considered an expected idleness?

(\#) 5.2 When authors are considering an expected idleness, it is explained how actual performance data were collected and analyzed?

$94 \%$

$47 \%$

$59 \%$

$59 \%$

$35 \%$

$24 \%$

$41 \%$

$29 \%$

$47 \%$

$47 \%$

$29 \%$

$41 \%$

$53 \%$

$\begin{array}{lllllll}41 \% & 53 \% & 0 \% & 0 \% & 0 \% & \begin{array}{l}\text { Strongly } \\ \text { Suggested, } \\ \text { but not } \\ \text { mandatory }\end{array} & \text { Introduction } \\ 29 \% & 35 \% & 29 \% & 6 \% & 0 \% & \text { Mandatory } & \text { Introduction }\end{array}$

$0 \%$

$12 \%$

$24 \%$

$35 \%$

$47 \%$

$24 \%$

$12 \%$

$29 \%$

$24 \%$

$29 \%$

$35 \%$

$41 \%$

$18 \%$

$0 \%$

0\%

$41 \%$

$18 \%$

$12 \%$

$0 \%$

Mandatory

Mandatory

Mandatory

Strongly

Suggested

but not

mandatory

$53 \%$

$35 \%$

$0 \%$

$6 \%$

$0 \%$

Mandatory

Mandatory

$29 \%$

$12 \%$

$0 \%$

$6 \%$

Mandatory

$24 \%$

$24 \%$

$0 \%$

$12 \%$

Mandatory
Methods

Methods

Methods

Discussion

Introduction

Methods

Methods

Methods

Methods

Results

Results

Methods

Results

Results

Methods

Methods

Methods

Methods

Methods 
Table 3 The consensus statement for TDABC studies in healthcare in a checklist format (Continued)

\begin{tabular}{|c|c|c|c|c|c|c|c|}
\hline TDABC elements & Mandatory & $\begin{array}{l}\text { Strongly } \\
\text { suggested, } \\
\text { but not } \\
\text { mandatory }\end{array}$ & Suggested & Option & $\begin{array}{l}\text { Do not } \\
\text { include }\end{array}$ & Classification & $\begin{array}{l}\text { Paper } \\
\text { section }\end{array}$ \\
\hline $\begin{array}{l}\text { (\#) } 6.1 \text { Are authors explaining how time data were } \\
\text { collected? }\end{array}$ & $76 \%$ & $18 \%$ & $6 \%$ & $6 \%$ & $0 \%$ & Mandatory & Methods \\
\hline $\begin{array}{l}\text { (\#) } 6.2 \text { Are authors using interviews with professionals } \\
\text { crossed with medical record review to estimate time } \\
\text { data? }\end{array}$ & $29 \%$ & $53 \%$ & $18 \%$ & $0 \%$ & $0 \%$ & $\begin{array}{l}\text { Strongly } \\
\text { Suggested, } \\
\text { but not } \\
\text { mandatory }\end{array}$ & Methods \\
\hline $\begin{array}{l}\text { (\#) } 6.3 \text { When using chronanalysis, it is being } \\
\text { explained how the sample of data was defined? }\end{array}$ & $35 \%$ & $35 \%$ & $12 \%$ & $6 \%$ & $6 \%$ & Mandatory & Methods \\
\hline $\begin{array}{l}\text { (\#) } 6.4 \text { Is it being explained if the chronanalysis } \\
\text { used a digital technology to collect real time } \\
\text { data, such as mobile app, wearable, drone, etc.? }\end{array}$ & $12 \%$ & $47 \%$ & $29 \%$ & $12 \%$ & $0 \%$ & $\begin{array}{l}\text { Strongly } \\
\text { Suggested, } \\
\text { but not } \\
\text { mandatory }\end{array}$ & Methods \\
\hline $\begin{array}{l}\text { (\#) } 7.1 \text { Is the median or average cost per patient (or } \\
\text { per technology) being calculated? }\end{array}$ & $65 \%$ & $29 \%$ & $0 \%$ & $6 \%$ & $0 \%$ & Mandatory & $\begin{array}{l}\text { Result and } \\
\text { Discussion }\end{array}$ \\
\hline $\begin{array}{l}\left.{ }^{*}\right) 7.2 \text { Are authors presenting the cost per each } \\
\text { patient included in the sample? (Chart bar, table, } \\
\text { etc.)? }\end{array}$ & $41 \%$ & $29 \%$ & $24 \%$ & $6 \%$ & $0 \%$ & Mandatory & $\begin{array}{l}\text { Result and } \\
\text { Discussion }\end{array}$ \\
\hline $\begin{array}{l}\left.{ }^{*}\right) 7.3 \text { Is the median or average cost per activity on a } \\
\text { macro level being presented? }\end{array}$ & $53 \%$ & $18 \%$ & $29 \%$ & $0 \%$ & $0 \%$ & Mandatory & $\begin{array}{l}\text { Result and } \\
\text { Discussion }\end{array}$ \\
\hline $\begin{array}{l}\left({ }^{*}\right) 7.4 \text { Is the median or average cost per activity on a } \\
\text { micro level being presented? }\end{array}$ & $29 \%$ & $24 \%$ & $24 \%$ & $24 \%$ & $0 \%$ & Mandatory & $\begin{array}{l}\text { Result and } \\
\text { Discussion }\end{array}$ \\
\hline $\begin{array}{l}\text { (*) }^{*} .5 \text { Is the median or average cost per resource } \\
\text { being presented? }\end{array}$ & $41 \%$ & $35 \%$ & $18 \%$ & $6 \%$ & $0 \%$ & Mandatory & $\begin{array}{l}\text { Result and } \\
\text { Discussion }\end{array}$ \\
\hline $\begin{array}{l}\left(\#^{*}\right) 7.6 \text { Are authors performing capacity idleness } \\
\text { analysis? }\end{array}$ & $18 \%$ & $53 \%$ & $12 \%$ & $12 \%$ & $6 \%$ & $\begin{array}{l}\text { Strongly } \\
\text { Suggested, } \\
\text { but not } \\
\text { mandatory }\end{array}$ & $\begin{array}{l}\text { Result and } \\
\text { Discussion }\end{array}$ \\
\hline 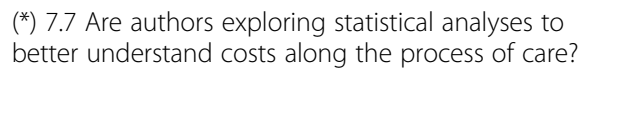 & $29 \%$ & $47 \%$ & $18 \%$ & $6 \%$ & $0 \%$ & $\begin{array}{l}\text { Strongly } \\
\text { Suggested, } \\
\text { but not } \\
\text { mandatory }\end{array}$ & $\begin{array}{l}\text { Result and } \\
\text { Discussion }\end{array}$ \\
\hline $\begin{array}{l}\left(\#^{*}\right) 7.8 \text { If the objective was to use the study to } \\
\text { support management and value decisions, are } \\
\text { authors reporting how value increasing was achieved } \\
\text { or if they are planning to achieve it? }\end{array}$ & $29 \%$ & $53 \%$ & $6 \%$ & $12 \%$ & $0 \%$ & $\begin{array}{l}\text { Strongly } \\
\text { Suggested, } \\
\text { but not } \\
\text { mandatory }\end{array}$ & $\begin{array}{l}\text { Result and } \\
\text { Discussion }\end{array}$ \\
\hline
\end{tabular}

The columns 'Mandatory, Strongly suggested, but not mandatory, Suggested, Option and Do not include' present the relative frequency of answers observed for each recommendation level. The column 'Classification' contains the final level of recommendation attributed for each element, and the 'Paper Section' column indicates which article section each element should be posted by the authors

existence of a framework in a checklist format contributes to clarifying the communication among all team members. Once we have a better comprehension about the sequence of steps that may be followed in a TDABC project, we believe that the methodological rigor for applying the TDABC can be easily evaluated, contributing to the homogeneity of the studies and consequently to the reproducibility of results. This Consensus statement coincided with the creation of a global network of TDABC researchers, the TDABC Consortium, which can further contribute to the global dissemination of the standards of TDABC research reporting, the research that is still mostly concentrated in the USA $[9,15]$.
TDABC is valuable because of its detailed reporting on the episode of care, as it identifies how patients consume resources along the process of care. Therefore, if well-constructed, this method can be used to optimize the care cycle [31], [41], resulting in cost-saving outcomes [22]. If authors apply their TDABC strategies with higher methodological rigor, the results from parallel studies can be compared and replicated, opening new avenues to redesign initiatives to optimize care cycles in different healthcare settings [22]. We believe that by the achieving homogeneity and accuracy in studies that applied TDABC in healthcare, the cost information can be more efficiently used for health economic analysis to guide decisions about issues such as the incorporation of 
health technologies, economic evaluation of healthcare cycle redesign, healthcare system management, reimbursement policies evaluation, and the identification of waste reduction opportunities in clinical pathways.

The use of TDABC to identify benchmarks of care pathways is a valuable application of the method in the context of VBHC [15]. However, once the method is being used to evaluate or compare costs and care pathways internationally, authors must take into consideration the study's economic assessment perspective and each healthcare system's context before accepting conclusions about costs and efficiencies based on system's results. Recently, a TDABC study compared the potential costsavings in implementing what were judged to be costeffective coronary artery bypass graft surgeries performed by top Indian hospitals in contrast to USA hospitals. The study concluded that the implementation of best practices observed in Indian hospitals would require modifications in regulations, family participation in the care process, and stronger support by hospital executives and clinicians [35].

At this time, the standardized framework for TDABC is supported by the literature and by the opinions of specialists with experience in applying TDABC in healthcare, although there is a lack of real-world full applications of the frameworks, and is therefore a research limitation. Our selection of experts was based on previously published TDABC studies, but we understand that with the application of the framework, methodological improvements from additional studies can be added to the framework. Also, the framework was designed in the context of healthcare business environment, even though the TDABC method was initially developed to increase the accuracy of unitary cost information in companies with high indirect costs in a variety of business sectors [37]. Once our standardized reporting framework establishes standardized reporting of healthcare studies, a similar process can be used to adapt it to any business sector.

Regarding the TDABC in Healthcare Consortium that has helped organize this work, this consensus statement helps introduce this innovative and global network. We believe that there are future opportunities for the development of international collaborative research and conferences for knowledge sharing to consolidate scientific advances for TDABC in the VBHC context.

\section{Conclusion}

In conclusion, this Consensus Statement introduces a standardized framework, in a checklist format, for the application of TDABC to encourage researchers to perform higher quality TDABC costing studies that can be replicated, contributing to scaling of strategies that result in cost-savings in healthcare and other fields.
Additionally, we believe that the standardized framework for healthcare and the creation of the TDABC Consortium can help connect and guide researchers, administrators, and other key decision-makers on how to quantitatively evaluate the impact of each strategy in projects designed to increase value in healthcare.

Future research should evaluate the benefits of the use of the TDABC standardized framework to report, in a scientific forum, TDABC projects developed in the context of healthcare business environment. This would help ensure the quality and interpretation of subsequent TDABC studies and help generate accurate cost information to support future decision-making processes.

\section{Appendix}

https://forms.gle/b38VGT8Frm4ED7yCA

\section{Supplementary Information}

The online version contains supplementary material available at https://doi. org/10.1186/s12913-020-05869-0.

Additional file 1. Most cited TDABC research in healthcare articles.

\section{Abbreviations}

TDABC: Time-driven Activity-based Costing; VBHC: Value-based Healthcare; CHEERS: Consolidated Health Economic Evaluation Reporting Standards; SPAQI: Society for Perioperative Assessment and Quality Improvement; ISPOR: International Society for Pharmacoeconomic and Outcomes Research

\section{Acknowledgements}

We would like to acknowledge the researchers who collaborated participating of the Focus Group workshop and by answering the questionnaire:

Focus Group Workshop: Bruna S Zanotto, Karen B Rushel, Leonardo Ogliari. Questionnaire answers: Mitchell Tsai, Aaaron Laviana, Jonathan C. Simmonds, Bruno Krug, Marcia Makdisse, Joana Siqueira de Souza, Cephas Chikanda, Kelvin Memeh, Richard Charter, Jessica Maxwell, Aoife Molloy, Omar MatukVillazon, Nelda van Soelen, Bavahuna Manoharan and Christer Mjåset, Pei-Fen Lin, Martina Yurgel.

\section{Authors' contributions}

APBSE: reviewed the articles, structured the questionnaire, organized the Focus Group Workshop conducted the data analysis, has been involved with all the writing process. CAP: reviewed the methods and results, has been involved with all the writing process. RU: structured the questionnaire, reviewed the methods and results, has been involved with all the writing process. All authors have read and approved the manuscript

\section{Funding}

This study was supported by the National Institute of Science and Technology for Health Technology Assessment (IATS/INCT, CNPq, project: 465518/2014-1) and the Coordenação de Aperfeiçoamento de Pessoal de Nível Superior (CAPE S), providing student grant for two of the authors. The authors who received the founding worked on the design of the study, the data collection and analysis, and on the interpretation of data and in writing the manuscript.

\section{Availability of data and materials}

The tables presented along the entire article contains most data used to develop the article analysis. Additional datasets used during the current study are available from the corresponding author on reasonable request. 


\section{Ethics approval and consent to participate}

The interviewees were invited to answer the questionnaire and consented to participate by having their opinions provided on the questionnaire included in the research analysis.

This research was conducted by the National Institute of Science and Technology for Health Technology Assessment (IATS)- CNPq/Brazil, which approved the conduct of the research. How the research is not involving patient data, animals or personal human information, the approval by the ethics committee was waived by the Ethical committee, being the ethics approval 'not applicable'.

\section{Consent for publication}

Not applicable

\section{Competing interests}

The authors declare that they have no conflicts of interest.

\section{Author details}

${ }^{1}$ National Institute of Science and Technology for Health Technology Assessment (IATS)- CNPq/Brazil (project: 465518/2014-1), Ramiro Barcelos 2350, Porto Alegre, Brazil. ${ }^{2}$ School of Technology, Pontifícia Universidade Católica do Rio Grande do Sul, Porto Alegre, Brazil. ${ }^{3}$ Programa de Pós-graduação em Epidemiologia da Escola de Medicina da Universidade Federal do Rio Grande do Sul, Porto Alegre, RS, Brazil. ${ }^{4}$ http:// www.tdabcconsortium.com/. ${ }^{5}$ Hospital Moinhos de Vento, Porto Alegre, Brazil. ${ }^{6}$ Department of Anesthesiology, Perioperative and Pain Medicine, Brigham and Women's Hospital/Harvard Medical School, Boston, MA, USA. ${ }^{7}$ Center for Perioperative Research, Brigham and Women's Hospital, Boston, MA, USA.

\section{Received: 3 June 2020 Accepted: 27 October 2020}

Published online: 01 December 2020

\section{References}

1. Martin JA, Mayhew CR, Morris AJ, Bader AM, Tsai MH, Urman RD. Using time-driven activity-based costing as a key component of the value platform: a pilot analysis of colonoscopy, aortic valve replacement and carpal tunnel release procedures. J Clin Med Res. 2018;10(4):314-20.

2. French $\mathrm{KE}$, Albright $\mathrm{HW}$, Frenzel JC, Incalcaterra JR, Rubio AC, Jones JF, Feeley TW. Measuring the value of process improvement initiatives in a preoperative assessment center using time-driven activity-based costing. Healthcare. 2013;1(3-4):136-42.

3. Dutta SW, Bauer-Nilsen K, Sanders JC, Trifiletti DM, Libby B, Lash DH, Lain M, Christodoulou D, Hodge C, Showalter TN. Time-driven activity-based cost comparison of prostate cancer brachytherapy and intensity-modulated radiation therapy. Brachytherapy. 2018;17(3):556-63.

4. da Silva Etges APB, Cruz LN, Notti RK, Neyeloff JL, Schlatter RP, Astigarraga CC, Falavigna M, Polanczyk CA. An 8-step framework for implementing time-driven activity-based costing in healthcare studies. Eur J Health Econ. 2019; [cited 2019 Jul 11]. Available from: http://link.springer.com/10.1007/s1 0198-019-01085-8.

5. Goldraich LA, Neyeloff JL, da Silva Etges APB, Zeilmann LG, Hastenteufel LT, Ghisleni EC, Clausell N. Heart transplantation cost composition in Brazil: a patient-level microcosting analysis and comparison with international data. J Card Fail. 2018;24(12):860-3.

6. Bobade RA, Helmers RA, Jaeger TM, Odell LJ, Haas DA, Kaplan RS. Timedriven activity-based cost analysis for outpatient anticoagulation therapy: direct costs in a primary care setting with optimal performance. J Med Econ. 2019;22(5):471-7.

7. El Alaoui S, Lindefors N. Combining time-driven activity-based costing with clinical outcome in cost-effectiveness analysis to measure value in treatment of depression. PLoS One. 2016;11(10).

8. Campanale C, Cinquini L, Tenucci A. Time-driven activity-based costing to improve transparency and decision making in healthcare. Qual Res Account Manag. 2014;11(2).

9. Keel G, Savage C, Rafiq M, Mazzocato P. Time-driven activity-based costing in health care: a systematic review of the literature. Health Policy. 2017; 121(7):755-63.

10. Alves RJV, da Silva Etges APB, Neto GB, Polanczyk CA. Activity-based costing and time-driven activity-based costing for assessing the costs of cancer prevention, diagnosis, and treatment: a systematic review of the literature. Value Health Reg Issues. 2018;17:142-7.

11. Gabriel L, Casey J, Gee M, Palmer C, Sinha J, Moxham J, Colegate-Stone TJ. Value-based healthcare analysis of joint replacement surgery for patients with primary hip osteoarthritis. BMJ Open Qual. 2019;8(2):e000549.

12. Kaplan RS, Porter ME. How to solve the cost crisis in health care. Harv Bus Rev. 2011;89(9):46-52.

13. Porter ME, Lee TH. The strategy that wilt fix health care. Harv Bus Rev. 2013; 91(10):50-+.

14. Allin O, Urman RD, Edwards AF, Blitz JD, Pfeifer KJ, Feeley TW, Bader AM. Using time-driven activity-based costing to demonstrate value in perioperative care: recommendations and review from the Society for Perioperative Assessment and Quality Improvement (SPAQI). J Med Syst. 2020;44(1):25.

15. da Silva Etges APB, Ruschel KB, Polanczyk CA, Urman RD. Advances in value-based healthcare by the application of time-driven activity-based costing for inpatient management: a systematic review. Value Health. 2020

16. Husereau D, Drummond M, Petrou S, Carswell C, Moher D, Greenberg D, Augustovski F, Briggs AH, Mauskopf J, Loder E. Consolidated health economic evaluation reporting standards (CHEERS) —explanation and elaboration: a report of the ISPOR health economic evaluation publication guidelines good reporting practices task force. Value Health. 2013;16(2):231-50.

17. Tan SS, Rutten FFH, van Ineveld BM, Redekop WK, Hakkaart-van RL. Comparing methodologies for the cost estimation of hospital services. Eur J Health Econ. 2009;10(1):39-45.

18. Drummond MF, Sculpher MJ, Torrance GW, O'Brien BJ, Stoddart GL. Methods for the economic evaluation of health care programmes. 3rd ed. Oxford: Oxford University Press; 2005. p. 396.

19. Elias KM, Stone AB, McGinigle K, Jo'An IT, Scott MJ, Fawcett WJ, Demartines $\mathrm{N}$, Lobo DN, Ljungqvist O, Urman RD. The reporting on eras compliance, outcomes, and elements research (recover) checklist: a joint statement by the ERAS ${ }^{\bullet}$ and ERAS ${ }^{\oplus}$ USA societies. World J Surg. 2019:43(1):1-8.

20. Akhavan S, Ward L, Bozic KJ. Time-driven activity-based costing more accurately reflects costs in arthroplasty surgery. Clin Orthop Relat Res. 2016; 474(1):8-15.

21. Donovan CJ, Hopkins M, Kimmel BM, Koberna S, Montie CA. How Cleveland Clinic used TDABC to improve value. Healthc Financ Manage. 2014;68(6):84-9.

22. Yangyang RY, Abbas PI, Smith CM, Carberry KE, Ren H, Patel B, Nuchtern JG, Lopez ME. Time-driven activity-based costing: a dynamic value assessment model in pediatric appendicitis. J Pediatr Surg. 2017;52(6):1045-9.

23. McLaughlin N, Burke MA, Setlur NP, Niedzwiecki DR, Kaplan AL, Saigal C, Mahajan A, Martin NA, Kaplan RS. Time-driven activity-based costing: a driver for provider engagement in costing activities and redesign initiatives. Neurosurg Focus. 2014:E3.

24. Kaplan RS. Improving value with TDABC; 2014

25. Popat K, Gracia KA, Guzman AB, Feeley TW. Using time-driven activity-based costing to model the costs of various process-improvement strategies in acute pain management. J Healthc Manag. 2018;63(4):e76-85.

26. Wong LP. Focus group discussion: a tool for health and medical research. Singap Med J. 2008;49(3):256-60.

27. Zanotto BS, da Etges APBS, Siqueira AC, da Silva RS, Bastos C, de Araujo AL, de Moreira TC, Matturro L, Polanczyk CA, Goncalves M. Economic evaluation of a telemedicine service to expand primary health care in Rio Grande do Sul: TeleOftalmo's microcosting analysis. Cien Saude Colet. 2020;25:1349-60.

28. McDermott JH, Caiola SM, Kuhn KF, Stritter FT, Beza J. A Delphi survey to identify the components of a community pharmacy clerkship. Am J Pharm Educ. 1995;59(4):334-41.

29. McMillan SS, King M, Tully MP. How to use the nominal group and Delphi techniques. Int J Clin Pharm. 2016;38(3):655-62.

30. Feeley TW, Mohta NS. Transitioning payment models: fee-for-service to value-based care. New Engl J Med Catalyst. 2018.

31. Shrank WH, Rogstad TL, Parekh N. Waste in the US health care system: estimated costs and potential for savings. JAMA. 2019.

32. McBain RK, Jerome G, Warsh J, Browning M, Mistry B, Faure PAl, Pierre C, Fang AP, Mugunga JC, Rhatigan J, Leandre F, Kaplan R. Rethinking the cost of healthcare in low-resource settings: the value of time-driven activitybased costing. BMJ Glob Health. 2016;1(3):e000134.

33. Cooper R, Kaplan RS. Measure costs right: make the right decision. Harv Bus Rev. 1988;66(5):96-103. 
34. McLaughlin N, Upadhyaya P, Buxey F, Martin NA. Value-based neurosurgery: measuring and reducing the cost of microvascular decompression surgery. Neurosurg. 2014;121(3):700-8.

35. Erhun F, Kaplan R, Narayanan V, Brayton K, Kalani M, Mazza M, Nguyen C, Platchek T, Mistry B, Mann R. Are cost advantages from a modern Indian hospital transferable to the US? Am Heart J. 2020.

36. Lee KK, Austin JM, Pronovost PJ. Developing a measure of value in health care. Value Health. 2016;19(4):323-5.

37. Kaplan RS, Anderson SR. Time-driven activity-based costing: a simpler and more powerful path to higher profits. Vol. 82, Harvard Business School Press Books. Boston: Harvard Business School Publishing Corporation; 2007. p. 266

\section{Publisher's Note}

Springer Nature remains neutral with regard to jurisdictional claims in published maps and institutional affiliations.

Ready to submit your research? Choose BMC and benefit from:

- fast, convenient online submission

- thorough peer review by experienced researchers in your field

- rapid publication on acceptance

- support for research data, including large and complex data types

- gold Open Access which fosters wider collaboration and increased citations

- maximum visibility for your research: over $100 \mathrm{M}$ website views per year

At BMC, research is always in progress.

Learn more biomedcentral.com/submissions 